\title{
Analysis of atmospheric circulation condition during severe thunderstorms in Yakutia in 2009- 2016
}

\author{
Lena Tarabukina ${ }^{1 *}$, Nina Kononova ${ }^{2}$, Vladimir Kozlov ${ }^{1}$ and Dmitriy Innokentiev ${ }^{1}$ \\ ${ }^{1}$ Yu.G. Shafer Institute of Cosmophysical Research and Aeronomy of the Siberian Branch of the \\ Russian Academy of sciences, Yakutsk, Russian Federation \\ ${ }^{2}$ Institute of Geography of the Russian Academy of sciences, Moscow, Russian Federation
}

\begin{abstract}
The days with large number of lightning discharges in Yakutia and its central part were associated with atmospheric circulation types classified by method of B.L. Dzerdzeevskii. The daily lightning number was obtained by three lightning location systems detecting radiopulses of very low frequency radiated by lightning discharges. The days with intense thunderstorms were selected by the 0.7 level of maximum lightning number in summer season, and the days of minimum lightning activity were selected by 0.3 level of maximum. The elementary circulation mechanisms (ECM) were revealed for severe thunderstorms in Yakutia: ECM 8a, 8dw, 9a, 12a of north meridional circulation group, ECM $13 \mathrm{~s}$ of south meridional circulation, ECM 2b of zonal circulation and ECM 3 of the disturbace of zonal circulation. Generally, the intense thunderstorms were associated with cyclones of southern outlets of Far East summer monsoon and outlets moving from southwestern.
\end{abstract}

\section{Introduction}

The problem of relation between thunderstorms and synoptic processes remains open for individual regions. As it was found in [1], atmospheric circulation macro processes last as series of long epochs. Thus to improve the understanding of connection between considered processes it is necessary to update the solution to the modern period. The probability of thunderstorm occurrence assessed by indices of atmospheric instability is much lower than the forecasting of other weather conditions. Such meteorological indices describe the state of mesoscale convective instability through standard parameters of temperature and humidity at different pressure levels [2].

The meteorological state of thunderstorms is formed by atmospheric circulation, which has a complex interrelated character throughout the northern hemisphere. The meteorological state of thunderstorms in Central Yakutia was described in earlier works [3]. However, as mentioned above, the circulation epochs change each other with decades and are determined by the prevalence of some circulation type in certain long periods. The continuous observations let to describe lightning activity in dependence of any circulation period. The

\footnotetext{
* Corresponding author: tarabukina@ikfia.ysn.ru
} 
Institute of Cosmophysical Research and Aeronomy of the SB RAS carries out the long-term instrumental observations of very low frequency (VLF) radio pulses in north-east part of Russia. As the main source of VLF pulses, the parameters of lightning activity in Yakutia were particularly studied [4].

\section{Equipment}

Lightning activity in Yakutia is observed by several lightning location systems (LLS) that detect VLF electromagnetic radiation of lightning strokes. The VLF radio pulse (sferic) propagates with weak attenuation between ground and low layers of ionosphere on a long distance (order of $\mathrm{Mm}$ ). The detection of all these systems is based on similar method - a rod antenna is connected to a laptop through preamplifier and analog-to-digit converter. The exact time of sferic arrival is determined by GPS-receiver. The systems detect individual strong lightning stroke, so the total number of recorded lightning signals consists of subsequent return strokes number produced by multiple lightning flash. The multiple lightning flash contains 2-4 strokes in average [5]. In this paper, we consider the data of three LLS - one-point lightning detector Stormtracker of Boltek Corporation, one-point lightning detector designed by ShICRA SB RAS and world wide lightning location network (WWLLN). The Stormtracker was installed in the centre of Yakutsk in 2009. The effective radius of detection is claimed to be 300 miles or $480 \mathrm{~km}$. The shortest detection radius was set as $60 \mathrm{~km}$ in post processing because of the noise resulting great number of pulses near the centre point. The detector is sensitive to noise component and components of short range lightning flash that are not return strokes. The Stormtracker device allow monitoring lightning activity in the central part of Yakutia. The SHICRA detector is located $27 \mathrm{~km}$ from Yakutsk, where there is no industrial noise. Its estimated radius of detection is about 1200 $\mathrm{km}$ in summer and the shortest radius is around $200 \mathrm{~km}$. The ShICRA detector has two different modes in summer and winter. The amplitude threshold is changed twice a year to detect strokes from local and distant thunderstorms. Unfortunately, the data have relatively low responsibilities as continuous series because of the occasional power outages. The WWLLN station was installed in Yakutsk in 2009 [6]. The WWLLN has about 60 stations over the world. The lightning location method is based on the difference of sferic arrival time to at least five stations [7]. The WWLLN detects both cloud-to-cloud and cloud-to-ground lightning strokes, the detection depends on current of lightning stroke. The system often selects signals of strong lightning strokes: the estimated detection efficiency was more than $25 \%$ for lightning currents more than $40 \mathrm{kA}$ and about $15 \%$ for any type of lightning strokes in 2012 [8-9]. In the paper, the lightning strokes were selected in the area with radius of 1200 $\mathrm{km}$ around Yakutsk.

The atmospheric circulation is classified by B.L. Dzerdzeevskii method [10-11]. The classification is based on the position of pressure systems throughout the northern hemisphere. There are 41 elementary circulation mechanisms (ECM) representing 13 types combined in 4 groups: zonal circulation, disturbance of zonal circulation, north meridional and south meridional circulation. The zonal circulation and its disturbance group represent cyclones development on the middle and tropical latitudes. The north circulation group is associated with the arctic air mass invasion to the middle latitudes. The south circulation group is associated with low-pressure system over polar latitudes. Each ECM is associated with some dynamical scheme defining cyclones movement and areas of high pressure in the northern hemisphere. The annual data on atmospheric circulation with daily time resolution are posted on the following website: www.atmospheric-circulation.ru. The daily meteorological state was described by using ERA-Interim and NCEP/NCAR reanalysis data: geopotential height, wind vector and temperature at some pressure levels $(500,700,850$, and $950 \mathrm{mb}$ ), precipitation and cloud cover. 


\section{Common features of lightning activity in Yakutia}

The thunderstorm season in Central Yakutia usually lasts from late May to early September. The season is longer in South Yakutia. The severe thunderstorms occur often in June-August, therefore in the study we consider June-August period. Lightning activity was high (the annual number of detected lightning strokes was greater than 7-years average) in 2011, 2014, and 2015 (fig.1). The variation of lightning stroke number in the Central Yakutia differed from the variation of total lightning number in Yakutia in 2010 when the peak lightning number was throughout Yakutia but it was not in the central part. The thunderstorms in South Yakutia resulted large number of sferics in 2010. In the data of ShICRA's detector was a gap in 2010 because of the instrumental outages.

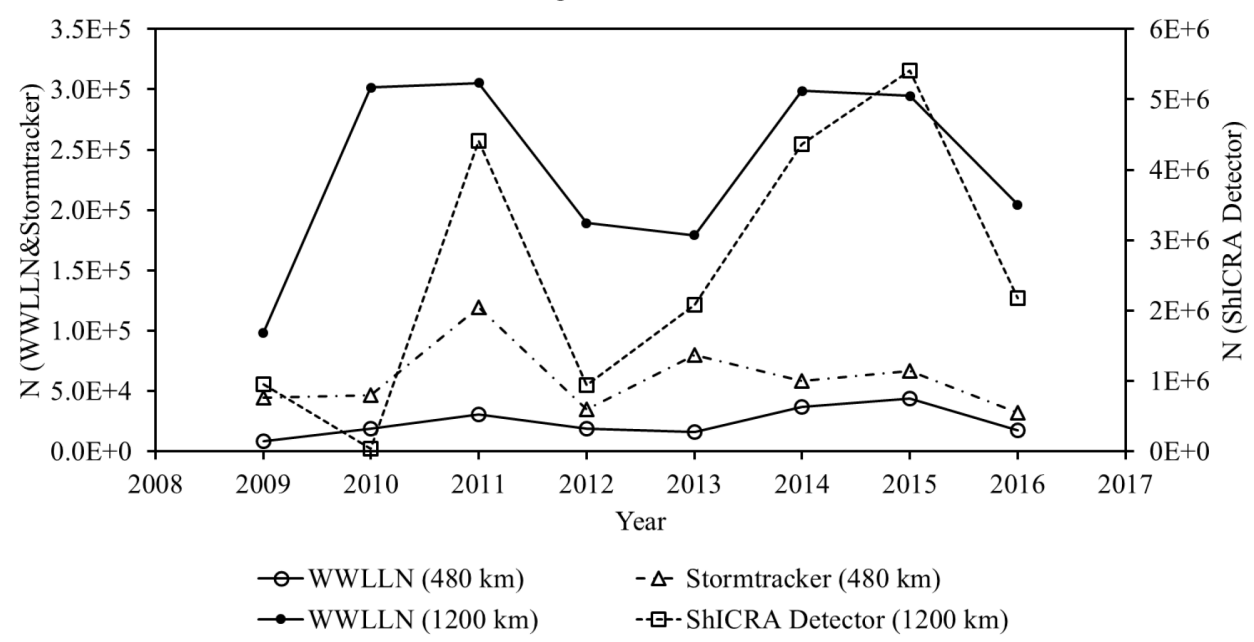

Fig. 1. The variation of annual sferics number detected by two one-point detectors and WWLLN (the area of location was limited in post-processing according to the radius of one-point detector).

The thunderstorm season in Yakutia has 2 or 3 local peaks that are higher than 0.7 of daily maximum. The season maximum varied around the middle of summer as expected (fig. 2). The peak varied from the end of July or the beginning of August to middle of June in 20122013. In 2014, the peak occurred in late July. It shifts to the beginning of July in 2015-2016. This process can be interpreted as interannual oscillation with period of $\sim 3$ years.

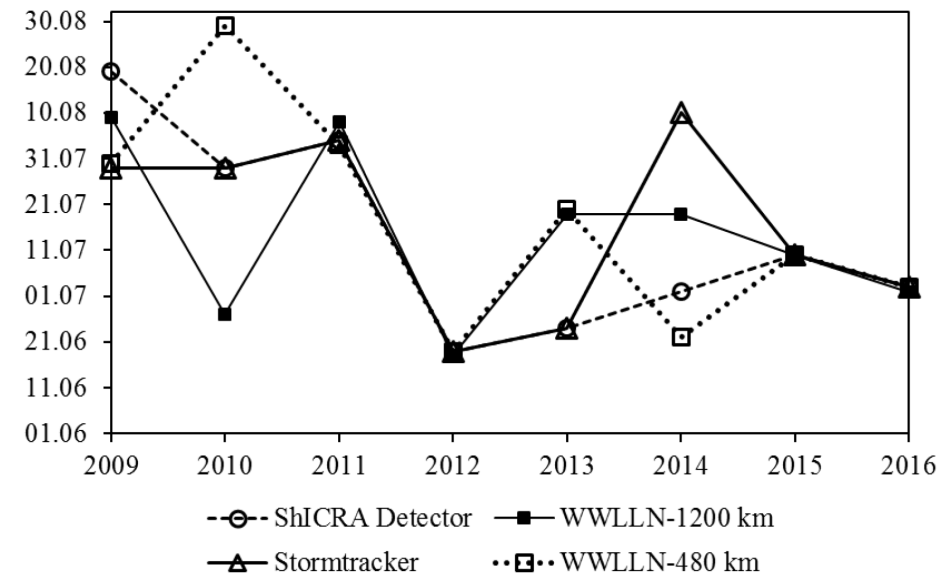

Fig. 2. The variation in date of daily lightning stroke number maximum. 


\section{Severe thunderstorms and atmospheric circulation}

The most intense thunderstorms (the daily lightning number was higher than 0.7 of seasonal maximum) were associated with ECM 8a, 8dw, 9a, 12a of north meridional circulation (for whole northern hemisphere), ECM $13 \mathrm{~s}$ of south meridional circulation group, ECM $2 \mathrm{~b}$ of zonal circulation group, and ECM 3 of zonal circulation disturbance group. The days before peak of lightning activity were also associated with same ECM and in addition with ECM $10 \mathrm{~b}$ and $8 \mathrm{cs}$ of north meridional group. The dynamic schemes show some common features: cyclonic activity develops in Siberian region and belongs to latitudinal western group of Siberian sector; there is an outlet from south-west in Yakutia area (between Baikal Lake and Amur River valley). During the days of 8 and 12 types of ECM, the southern cyclone outlets induced thunderstorms development in Siberia and Far East. During the days with ECM 9a, $13 \mathrm{~s}$ and $2 \mathrm{~b}$, the thunderstorms in Siberia were formed on a front of north-west and south cyclones from Far East. During the days with ECM 3 the cyclones move along latitude and the arctic air mass invasion occurs in other regions of northern hemisphere. The ECM 10b is associated with dynamic development of cyclonic activity in Eastern Siberia while the south outlets are moving along Far East. The days with peak lightning activity (the number of lightning stroke is greater than $\sim 0.7$ of season maximum) in Central Yakutia observed by Stormtracker are usually associated with ECM 13s, 12a, and 3 (5, 4, 3 days correspondingly). The most frequent ECM were 9a, 12a and 13s in 2009-2016. Mostly, the severe thunderstorms (the lightning number was greater than 0.7 of season maximum, 17 days) occurred in 2 days after the change of selected ECM or before the change to next ECM.

The visualization of lightning strokes location with geopotential height and wind vector maps at level of $850 \mathrm{mb}$ and cloud cover (provided by the service https://worldview.earthdata.nasa.gov basing on data of MODIS on Aqua/Terra satellites) confirmed the results of joint analysis of ECM and lightning activity. The figure 3 demonstrates the sample of a severe thunderstorm in Central Yakutia and geopotential height spatial distribution. The greatest number of the intense thunderstorms in Central Yakutia (the daily lightning number was higher than $\sim 0.7$ of seasonal maximum by Stormtracker data) were caused by the cyclones moving from southern region between Baikal Lake and Amur River or just from Amur River direction $(\sim 81 \%)$. Other cases were associated with the cyclones moving from Western Siberia direction.

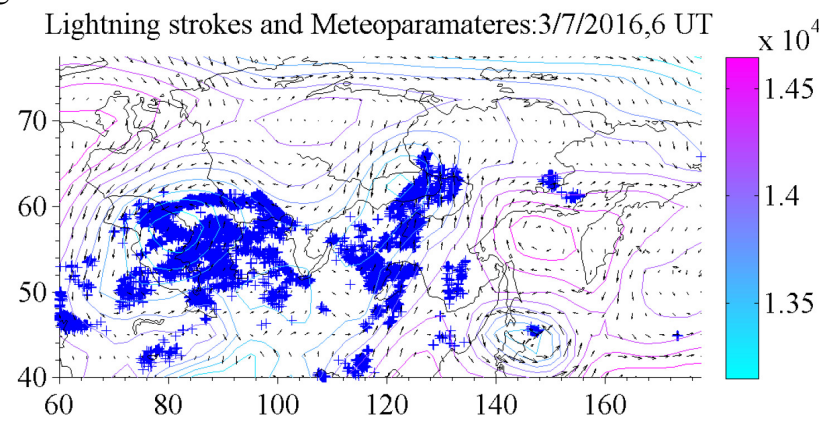

Fig. 3. The location of lightning strokes ("+" mark), geopotential height and wind vector at $850 \mathrm{mb}$ pressure level on July 3, 2016 at 6 UT (local time in Yakutia - 15 LT).

However, the mean daily number of lightning strokes during any summer days with selected ECM differed from the season mean daily number only less than 3\%. Although several ECM facilitated the thunderstorm processing in Yakutia, the ECM were not completely responsible for lightning activity. The correlation between variation of individual ECM frequency and lightning number in summer showed low significance (table 1). The exception was a correlation between WWLLN data and number of days with ECM $2 b$ and ECM 3: the day 
number with these ECMs was less than the days number with other ECMs, so these ECMs cannot influence on total lightning activity. The groups of ECMs combined by the similar features (the location of some pressure systems in Siberia) showed also nonsignificant values (table 2).

Table 1. The correlation coefficient between interannual variations in number of days with selected ECM and total number of lightning strokes in 2009-2016.

\begin{tabular}{|c|c|c|c|c|c|c|c|c|}
\hline Device $\backslash$ ECM & $2 \mathrm{~b}$ & 3 & $8 \mathrm{a}$ & $8 \mathrm{cs}$ & $9 \mathrm{a}$ & $10 \mathrm{~b}$ & $12 \mathrm{a}$ & $13 \mathrm{~s}$ \\
\hline Stormtracker & 0.05 & -0.18 & -0.1 & 0.15 & 0.12 & 0.45 & 0.35 & -0.42 \\
\hline $\begin{array}{c}\text { WWLLN (480 } \\
\mathrm{km})\end{array}$ & -0.60 & 0.63 & 0.02 & -0.18 & 0.52 & 0.24 & 0.05 & -0.25 \\
\hline ShICRA Det. & -0.32 & 0.52 & 0.18 & -0.21 & 0.23 & 0.55 & 0.00 & -0.28 \\
\hline $\begin{array}{c}\text { WWLLN (1200 } \\
\mathrm{km})\end{array}$ & -0.77 & 0.35 & -0.23 & -0.04 & 0.54 & -0.04 & 0.04 & -0.04 \\
\hline
\end{tabular}

Table 2. The correlation coefficient between interannual variations in number of days with groups of selected ECM and total number of lightning strokes in 2009-2016.

\begin{tabular}{|c|c|c|}
\hline Device $\backslash$ ECM & $10 \mathrm{~b}+12 \mathrm{a}+12 \mathrm{bs}$ & $3+6+8 \mathrm{a}+9 \mathrm{a}+13 \mathrm{~s}$ \\
\hline Stormtracker & 0.18 & -0.19 \\
\hline ShICRA Det. & 0.08 & -0.08 \\
\hline WWLLN $(1200 \mathrm{~km})$ & -0.3 & 0.43 \\
\hline
\end{tabular}

The cyclone fronts moving northward and northeastward might form severe thunderstorms in Yakutia. It is probably related to meridional epoch of atmospheric circulation that influence of monsoon activity in Far East with local orography. However, the relation of lightning activity in Yakutia and macroscale atmospheric processes is still difficult to describe statistically.

The research was funded by Russian foundation of basic research according to the research project № 18-35-00215, project № 18-45-140028, project № 17-05-41085, and Program II.16.2.1 (Number of registration AAAA-A17-117021450059-3).

\section{References}

1. N.K. Kononova, Fundamental and Applied Climatology 1, 1, 133-162 (2015)

2. T.V. Ershova, V.P. Gorbatenko, O.A. Klipova, TGPU Bulletin 122, 7, 9-14 (2012).

3. Ts.A. Shver, S.A. Izumenko, Climate of Yakutsk (Hydromet. 1982).

4. V.I. Kozlov, V.A. Mullayarov, Lightning activity in Yakutia (2004).

5. L.D. Tarabukina, V.I. Kozlov, Izvestiya. Atmospheric and Oceanic Physics 52, 3, 271276 (2016).

6. V.I. Kozlov, V.A. Mullayarov, R.R. Karimov, Sovr. Probl. Dist. Zond. Zemli iz Kosmosa 8, 3, 257-262 (2011).

7. R.L. Dowden, J.B. Brundell, C.J. Rodger, J. Atmos. Solar-Terr. Phys. 64, 7, 817-879 (2002).

8. S.F. Abarca, K.L. Corbosiero, T.J. Galarneau, J. Geophys. Res. 115, D18206 (2010).

9. M.L. Hutchins, R.H. Holzworth, C.J. Rodger, S. Heckman, J.B. Brundell, EGU General Assembly Conference Abstracts 14, 12917 (2012).

10. B.L. Dzerdzeevskii, Selected Works. General circulation of the atmosphere and climate (Nauka, 1975). 
11. N.K. Kononova, Classification of circulation mechanisms of northern hemisphere (2009) 